\title{
Optyka obcości. Ludzkie wiersze o zwierzętach
}

\section{Strangeness Optics. Human poems about animals}

\author{
|Agata Szulc-Woźniak
Uniwersytet im. Adama Mickiewicza w Poznaniu
}

\begin{abstract}
The article questions the post-anthropocentric ability of Joanna Pollakówna's poems. Poet, Ph.D holder in history of art, rooted in the European culture and Christian thought (St. Augustine, St. John of the Cross, Pascal), seems to be close to the traditional values of humanism (humanisms). She takes up themes of pain and suffering, adds religious and philosophical meanings along with anthropocentric perspective inscribed so deeply into them that it is sometimes barely visible. At one time, in her work, she is looking for relationship and intimacy with non-human beings - at other times recognizing the equality of all beings towards the biological life (zoe).

In the following text I present the selected Pollakówna's poems representing her writing and containing reflections about animals. In this way, I try to outline the poet's two directions of considerations of non-human beings - striving towards relationships and the delight of their impossible to tame nature.
\end{abstract}

Key words: Joanna Pollakówna, human and non-human animals, animal studies, posthumanism, non-anthropocentric ideas, poetry

Streszczenie: Artykuł stawia pytanie o możliwość postantropocentrycznej lektury wierszy Joanny Pollakówny. Poetka, doktor historii sztuki, zakorzeniona w kulturze europejskiej i myśli chrześcijańskiej (św. Augustyn, św. Jan od Krzyża, Pascal), wydaje się bliska tradycyjnym wartościom humanizmu (humanizmów). Podejmując tematy bólu i cierpienia, przymierza do nich sensy religijne i filozoficzne, wraz z wpisaną w nie, tak głęboko, że niekiedy trudną do dostrzeżenia, perspektywą antropocentryczną. Równocześnie, w swojej twórczości, poszukuje relacji i bliskości z istotami nie-ludzkimi - dostrzegając równość wszystkich bytów wobec kolei biologicznego życia (zoe).

W tekście przedstawiam wybrane wiersze Pollakówny, reprezentatywne dla jej pisarstwa i zawartych w nim refleksji o zwierzętach. Zarysowuję w ten sposób dwa kierunki rozważań poetki o istotach nie-ludzkich - dążenie ku relacji i zachwyt ich niemożliwą do oswojenia naturą.

Słowa kluczowe: Joanna Pollakówna, istoty ludzkie i nie-ludzkie, animal studies, posthumanizm, postantropocentryzm, poezja 
Czy poezja może nie być antropocentryczna? Poetyce Arystotelesa, pierwszej z oczywistych adresatek tego pytania, trudno byłoby je nawet zadać. Oparta na fundamentalnej dla kultury europejskiej filozofii, nie pozostawia niedopowiedzeń prowokujących podobne wątpliwości. Stagiryta, który w traktacie $O$ duszy ustanowił trójdzielny, hierarchiczny podział bytów (ludzie, zwierzęta, rośliny), uznał rozum za specjalny przymiot człowieka, wyróżniający go spośród innych form życia (Gajewska 2015, 214215). Istot nie-ludzkich jako możliwych autorów nie uwzględniają i dalsze rozprawy teoretycznoliterackie wybitnych humanistów i wyznawców ratio, skupione bądź na źródłach pochodzenia poezji, bądź na jej wartościach lub wyznacznikach.

„Zwrot zwierzęcy” zaskoczył najważniejsze Artes poeticae. Próżno więc szukać ratunku tam, gdzie błądzący polonista trafia po omacku. Bo też formacja humanistyczna dotarła do pewnej granicy. Nowe technologie, odkrycia w dziedzinach biologii i genetyki wskazały na nierozerwalne związki między ludzkimi a nie-ludzkimi formami życia. Badania wielu gatunków zwierząt ujawniły ich samoświadomość, zdolność do racjonalnego działania, uczenia się i przekazywania języka (Weil 2014, 16). Odkrycie złożonej, symbiogenetycznej struktury naszych organizmów, który tworzą miliony istot, pozostających ze sobą w różnych stosunkach zależności (Margulis, Symbiotyczna planeta, za: Bakke 2010, 72), prowokuje wręcz pytanie o to, czy kiedykolwiek byliśmy ludźmi (Haraway 2008, 3-133). Przekonanie o całkowitej ontologicznej odrębności człowieka i jemu tylko właściwych przymiotach, fundament zachodniej filozofii i ludzkiej uprzywilejowanej pozycji w świecie, zdaje się chwiać w posadach (Graham, Representations of Post/ human. Monsters, Aliens and Others in Popular Culture, za: Bakke 2010, 17). Ma to szereg daleko idących konsekwencji dla humanistycznej refleksji akademickiej - etyki, kulturoznawstwa, studiów nad literaturą. Redaktorki niedawno wydanej monografii wieloautorskiej pt. Zwierzęta, gender i kultura. Perspektywa ekologiczna, etyczna i krytyczna zauważają:

Mimo oddziaływania głównie na wyobraźnię, studia nad zwierzętami zmieniły takie dyscypliny, jak literaturoznawstwo czy filozofię poprzez postawienie kluczowej kwestii: w jakim stopniu humanistyka odnosi się do realnych problemów zwierząt innych niż ludzie (...). Nie posiadając specjalistycznej wiedzy zoologicznej czy neurologicznej, która jest podstawą większości badań nad zwierzętami, a sam paradygmat naturalizowania świadomości zwierzęcia przeważa w debatach etycznych, sądzimy, że warto uwzględniać zapisy doświadczeń, reakcji afektywnych i estetycznych, wynikających z tych niezwykłych spotkań i zazębień ze światem zwierzęcym, których literatura czy refleksja filozoficzna stanowi twórcze i eksperymentalne medium (Barcz, Dąbrowska 2014, 9). 
Jeśli, jako czytelnicy poezji, zgodzimy się z decentralizacją człowieka (tylko czy ktokolwiek nas o taką zgodę pyta?), nie wystarczy nam przegląd peryferiów ani dyskretna rewizja ustalonych ścieżek krytycznych. Animal studies, które śmiało wkroczyły na teren badań literatury, oznaczają nie zwrot, ale ryzykowne salto-mortale, wzywające do reinterpretacji kanonu i dotychczasowych sposobów myślenia o wartości życia - wyłącznie ludzkiego, politycznego, bios, i biologicznego, właściwego każdej jednostce, zoe (Agamben 2008).

Czy poezja może nie być antropocentryczna? Czas odpowiedzieć na to, retorycznie intrygujące, choć chyba wewnętrznie sprzeczne, pytanie. Jako, definiowana ludzkim językiem, specyficznie ludzka forma komunikacji artystycznej nie może być ani tworzona, ani prawdziwie zamieszkiwana przez istoty nie-ludzkie. Czy samo poszukiwanie w poezji miejsca dla zwierząt nie jest przejawem „gatunkowizmu” (Singer 2004, 18) - wyrazem pychy, wiary w możliwość nazwania doświadczeń istot nie-ludzkich?

Zwierzęta nie piszą wierszy. Ale, jak zawsze, warto pomyśleć, że mogłoby być inaczej. W pojemnej definicji Jarosława Mikołajewskiego znalazłoby się chyba miejsce dla liryki nie-ludzkiej.

Poezja to mowa bezdomna, sieroca. Mowa, która bierze ze wszystkich języków świata, ale sama nie jest żadnym językiem: jest, w każdym swoim wcieleniu, jednorazową wypowiedzią, która powstaje, kiedy w umyśle poety lub w świecie dzieje się coś poza wszelkim porządkiem. Poeta to ten, który podczepia się pod mowę bezdomną, sierocą, w chwili, kiedy wszystkie mowy zagospodarowane i uładzone nie wystarczają do wypowiedzenia tego, co wypowiedzieć potrzeba koniecznie (Mikołajewski, cyt. za: Rybak 2009).

Punkt wyjścia: poczucie bezradności, wyobcowania, dojmującej niewyrażalności. Samotność i niepowtarzalność odczucia. Pierwsze obrazy? Krzywda, niesprawiedliwość. Niewola. Tak rozumianą poezję - poezję o bólu, wywłaszczoną z uporządkowanej narracji, wiodącą w poprzek jednomyślności systemów władzy, poezję poza mową - zwierzęta mogłyby tworzyć. I może tworzą. Ale trudno ją zrozumieć. Jest wyrażana w częściowo tylko zrozumiałych dla naszego oka i umysłu komunikatach ciała, które mogą rejestrować ludzcy poeci. Choć to bardzo trudne, czasem się udaje - twórcom najczulej i najwnikliwiej obserwującym świat, obdarzonym szczególną wyobraźnią. Takim jak Joanna Pollakówna.

Co potem - nie wiem.

Ale niech nadchodzi.

Jest jednak ulga w gasnącym ognisku;

Gruzełka żużlu w rubinowym błysku

zyska splendor i patos nadmorskich zachodów.

Bywa chwila godności, bezmierna wszechwiedza

owada leżącego bezwładnie na plecach,

kiedy nóżki w trzy krzyże układa na piersi 
- niepozorna kołyska przeogromnej śmierci

(Pollakówna 2012a, 388)

Spojrzenie jest poważne i badawcze - przenika pozory nieistotności, przemienia codzienną rzeczywistość w nieuchwytną tajemnicę. Mikroobserwacja wydaje się tak wnikliwa, że jest niemal namacalna. Bohaterów wiersza można sobie wyobrazić - owada, milczącego w cierpieniu i poetkę, pochyloną nad nim z szacunkiem i namysłem. Ich spotkanie nie ma $\mathrm{w}$ sobie nic $\mathrm{z}$ antropocentrycznej dialektyki podporządkowania i zależności - jest czystą bliskością, porozumieniem przekraczającym ograniczenia biologicznego gatunku i ludzkiego języka. Więź jest tworzona przez jednakowe doświadczenie, bohaterów wiersza łączy konieczność stanięcia w obliczu przeogromnego i niezrozumiałego.

Podobnie bliskość w związkach ludzko-zwierzęcych rozumie chyba Donna Haraway w słynnej już książce o współistnieniu i wzajemności - When species meet. Powołując się na rozważania Cary'ego Wolfe'a o ludzkich i nie-ludzkich gatunkach bycia-w-świecie, między którymi możliwe są szacunek, zrozumienie i oparta na komunikacji więź, filozofka zauważa, że do swoistego uwolnienia od myślenia hierarchizującego byty wiedzie zakwestionowanie prymatu języka. A więc tego, co stanowi o ludzkiej (wszech) mocy. Szczególnym polem do badań staje się tu porozumienie i wzajemna pomoc między zwierzętami a ludźmi z niepełnosprawnością (Haraway 2008, 371-372). Również w poezji Pollakówny tym, co najbardziej jednoczy pozornie obce, niezrozumiałe dla siebie światy, jest równość w obliczu najtrudniejszych wyzwań zoe, życia wpisanego w ciało (Rosochacka 2012) starzenia się, choroby, śmierci (Mazan-Mazurkiewicz 2016, 210).

Czy jednak w spotkaniu poetki z insektem rehabilitacji podlega życie w jego „nagim” wymiarze, życie rozumiane jako „absolutnie bierne, konstytutywne, zewnętrze" (Bednarek 2008)? I czy - tym samym - Pollakówna odpowiada na jedno $\mathrm{z}$ podstawowych wyzwań posthumanizmu (Bakke 2010, Rosochacka 2012)? Wydaje się, że nie. Owadzia egzystencja nie jest przecież tylko biologiczna - zyskuje sensy symboliczne, nawet religijne.

Dzięki bliskiej perspektywie obserwacji, drobne ciałko zwierzęcia w agonii zostaje swoiście powiększone - nabiera dostojeństwa i powagi: staje się symbolem istnienia stojącego na granicy własnego bycia, a może nawet - istnienia świadomego swojego kresu. Sześć odnóży układa się w trzy krzyże, jak na wzgórzu Golgoty, znak męki, ale i znak chwały - a także wspólnoty cierpienia. Chitynowy pancerz insekta, dotąd szkielet chroniący wewnętrzne narządy, odwrócony, upodobnia się do nieco groteskowej kołyski (kołyski-grobu) - bujającej do ostatniego snu.

W poetyckiej wyobraźni Pollakówny dzieciństwo i starość są sobie bardzo bliskie (Starość, Okno) - oba etapy życia łączy kruchość i niestałość. Oba kojarzą się z oczekiwaniem, byciem o krok przed przemianą - i wiążą się z, 
wpisaną w te kondycje, zależnością. „Chwila godności, bezmiernej wszechwiedzy” nie zdarza się na dłużej. Jest ulotna. Poetka mówi o niej - „bywa”.

Ten nieco zdawkowy czasownik, który, wbrew swojemu gramatycznemu przeznaczeniu, nie odpowiada na pytanie, co robi (każdy z bohaterów wiersza), wydaje się wieść ku jakiejś (chyba Jakiejś) nie-ludzkiej (ponad-ludzko-zwierzęcej) ingerencji. „Bywa” wskazuje na to, że dostąpienie wiedzy jest niezależne i od człowieka, i od owada - „bywa” pojawia się nagle i znikąd, bez nawiązania do poprzedniej strofy, ale w inicjalnym miejscu/ pozycji kolejnej, nadając śmierci, biologicznemu staczaniu się w nicość, sens i patos. „Bywa” należy do porządku spoza utworu, spoza opowieści o umierającym owadzie i współcierpiącej poetce. Swoim zjawieniem się w ośrodkowym miejscu wiersza, dzielącym go na strofy ludzką i ludzko-nie-ludzką, poświadcza, że obie cierpiące istoty są sobie niesłychanie bliskie w niezdarności pojęcia, niesamodzielności i niezborności bycia wobec przeogromnego końca. Alicja Mazan-Mazurkiewicz, opisując zwierzęce tropy u Pollakówny, zauważa:

Pogłębiona wizja rzeczywistości nakazuje odsunąć wszelką pokusę bezpiecznego dystansu wobec świata natury. Nawet gdy wydaje się on ludzkiej wrażliwości obcy, gdy może budzić grozę (jak zabawy młodych drapieżników), nie jest już światem obcym. Nie istnieje bowiem podział na ludzki - zrozumiały - i pozaludzki - niepojęty. Oba światy ogarnia ta sama tajemnica - oba zyskują sens (choć nie racjonalne wyjaśnienie) w odniesieniu do Boga. Następuje swoiste pojednanie z naturą w wymiarze poznawczym; w niemożności racjonalnego poznania. Zarazem niezborność, uporczywość, trud - nieustannie towarzyszące procesowi poznawczemu - to cechy człowieka (i ściślej: poety) niejednokrotnie w poezji Pollakówny obrazowane przez odwołanie do świata owadów (Mazan-Mazurkiewicz 2016, 207-208).

Biorąc pod uwagę bliskość egzystencjalnych doświadczeń poetki i owada, a także mikroskalę obserwacji, ciekawe i znaczące wydaje się, że insekt $\mathrm{z}$ wiersza nie ma nazwy gatunkowej. Bez tego doprecyzowania jest trudno uchwytny, trudno wyobrazić go sobie wyraźniej. Reprezentuje przecież najliczniejszą i najbardziej zróżnicowaną grupę stworzeń, którym poświęcamy wielostronicowe, szczegółowe atlasy, które zamykamy w gablotkach i terrariach, próbując zrozumieć, w ten, jakże ludzki i ograniczony sposób, ich niezwykłe bogactwo i niejednorodność. Jeśli poetka uznała nazwę owada za nieistotną, można by traktować to jako przejaw ograniczoności, niedoskonałości ludzkiego spojrzenia, nieczułego na szczegóły. Ale przecież Pollakówna patrzy uparcie i wnikliwie, z bliska. Pominięcie nazwy wydaje się więc celowe - autorka ignoruje ją jako coś nieistotnego. Może dlatego, że katalogi gatunków i sama tendencja do ich selekcjonowania wpisują się w dyskurs szowinizujący. To w jego ramach można mówić o insektach pożytecznych lub szkodnikach, klasyfikując owady wyłącznie ze względu na ich odniesienie do ludzi (Gzyra 2014, 10).

Umierające stworzenie $\mathrm{z}$ wiersza jest tajemnicą. Jego niewielkie rozmiary i pozorna anonimowość wskazują na to, że każda śmierć jest równie 
wielka. Owad ma więc chyba zadanie uogólnienia - jest obrazem każdego istnienia, kruchego, niesamodzielnego, skazanego na śmierć. Dotyczy też życia poetki. Obraz owada poprzedza przecież bardzo osobista strofa o niepewności własnego bycia. Jak w wielu innych utworach Pollakówny wrażliwość na drugiego wiedzie przez zrozumienie siebie.

Zbuduj w lesie ze światła zaporę sarni sen

przez splątane korzenie

przemknął jeleń

mrok zwiśnie w pionie

jesteś sarną owadem i okiem

sarny

i na trawach ważonym cieniem

pęka las w organowe kolory

wzbiera las pełen obcych zwierząt

zwierząt obcych o ogień

o kamień ostrzony

o osobność barwy i kory

jesteś cieniem w snach zwierząt zbudzonym.

(Zwierzęta Franza Marca - Pollakówna, 2012a, 102)

Pisanie o zwierzętach zawsze jest narażone na błędy: korzysta z ludzkiego języka, ogranicza je ludzkie rozumienie i ludzka potrzeba nadawania ludzkiego sensu. Do tego koniecznego zapośredniczenia Pollakówna dodaje kolejne. Medium dostarczającym wiedzy o istotach nie-ludzkich staje się malarstwo - jej „drugi świat widzialny”, który, jako historyczka sztuki, bada nie mniej wnikliwie niż obrazy codzienności.

Franz Marc, wspomniany w tytule wiersza, był ekspresjonistą, współzałożycielem grupy Der Blaue Reiter, blisko związanym z Wassilem Kandinsky'm. Tworzył na początku XX wieku, w Niemczech, w szczególnym momencie przełomu, jednocześnie kryzysu i rozkwitu sztuki, o którym Pollakówna pisze: „ważne (...) było chyba otwarcie wyobraźni na pewne śmiałości sztuki, jej samoprześmiewczy, przedrzeźniający timbre. I może - wykształcenie w sobie jakiejś optyki obcości, zdolności doznawania nigdy nie oswojonej natury świata" (Pollakówna 2012b, 326, podkr. A.Sz-W). Komentatorzy twórczości Marca zwracają uwagę na szczególną rolę zwierząt na jego płótnach - zdaniem Gabriele Crepaldi są one odpowiednikami aniołów w malarstwie renesansowym - wysłannikami zagubionych w świecie piękna i prawdy (Crepaldi 2006, 60). Malarz zmarł młodo, na froncie ludzkiej, rozpaczliwie brzydkiej bitwy pod Verdun.

O którym z licznych obrazów Marca poświęconych zwierzętom pisze Pollakówna? O jednym czy o wszystkich naraz - wyrażając esencję jego poszukiwań nieoswojonej natury? Jeśli o jednym - może o najsłynniejszym, Losie zwierząt z 1913 roku, uważanym za wyraz afirmacji życia 
w zdegenerowanym świecie (Dziewicki 2013). Na płótnie bios wydaje się potrzebować uwagi i troski - czysto, niemal czule, zarysowane sylwetki saren trzeba wypatrzeć wśród przemocy zdecydowanych barw. Zwierzęta są obce i prawdziwe. Niemożliwe do pojęcia - w plątaninie śmiałych kolorów, cieni i kształtów wydają się odległe i, choć widoczne, jednak skryte przed ludzkim okiem i myślą. Podobne połączenie prawdy o życiu i prawdy jego nieuchwytności odczytać można na innych płótnach malarza, mniej może dramatycznych, ale nie mniej interesujących - takich jak Sarny albo Tygrys. Pollakówna przepisuje artystyczne rozpoznania Marca niezwykle starannie.

"Optykę obcości” tworzy już forma utworu - pochwytująca wrażenie nieoswojenia. Jeleń przeskakuje „splątane korzenie” i część wersu. Z gęstwiny słów, mroku, pionu i światła nagle, jak z ciemnego lasu, na krótko i niespodziewanie, błyska oko. Płocha sarna ucieka przez całą linijkę. Znajduje dla siebie bezpieczne miejsce tam, gdzie nic nie można już powiedzieć - dopiero na jej krańcu. Umyka wszechwładnej mowie, pozostaje niedocieczoną tajemnicą. Oddech strofy zdradza popłoch i niepewność - można się w niej poczuć jak w pułapce.

Do znajomych miejsc nie prowadzi też kolejna część wiersza. Las pęcznieje kolorem i niepokojącą obcością zwierząt. W umiejętności rozpalania ognia i wytwarzania pierwszych narzędzi poetka szuka źródeł ludzkiego poczucia odrębności, wiodącego jednak nie do poczucia wyższości, a do lęku. Lęku przed niemożnością pojęcia świata, przed samotnością i dojmującą osobnością.

Czy bliskość i obcość na pewno się wykluczają? Pollakówna, stojąc przed obrazami Marca, zdaje się przymierzać do malarskich przedstawień dążenia charakterystyczne dla własnej twórczości - poszukiwanie porozumienia i bliskości. „Jesteś sarną owadem i okiem / sarny”. A nawet: „Jesteś cieniem w snach zwierząt zbudzonym". Antropocentryczna optyka niespodziewanie się odwraca - w lesie i w wierszu to człowiek zależy od zwierzęcia. I zwierzę zdecyduje - czy śnić go dalej?

Co potem - nie wiem i Zwierzęta Franza Marca pochodzą z reprezentatywnego, dojrzałego etapu twórczości Pollakówny, pełnego rozmaitych stworzeń, w przeważającej części występujących w znanych poetce warunkach klimatycznych (szereg gatunków ptaków, owady, myszy, lisy, psy). Utwory wydają się więc zapisem autentycznych spotkań - lub przynajmniej dążenia do nich. Pollakówna dostrzega „nieoswojoność”, obcość zwierząt (Niewinność, Prośba o radar zwierzęcy), ale także bliskie pokrewieństwo (Prawo naturalne). Zdarza się, że prosi je o wybaczenie (Po śmierci kosmonauty).

Celnie zauważa Mazan-Mazurkiewicz, że obecność istot nie-ludzkich $\mathrm{w}$ wierszach poetki znamionuje przejście od zbiorowości do pojedynczości 
(Mazan-Mazurkiewicz 2016, 204). Zwierzęta, nie tylko w swoim bogactwie gatunkowym, ale i osobności, i niepowtarzalności poszczególnych istot, stają się Pollakównie coraz bliższe. Tendencja do uwyraźniania, uszczegóławiania, jakby poprawiania ostrości w soczewce, w pewnym momencie ulega jednak zmianie. „Bracia i siostry w bólu” (Wspólnota) w ostatnich tomach stopniowo i dyskretnie wycofują się z utworów. Zostawiają miejsce dla aniołów (Wysłannik) i światła. Dla samotnego zmagania się z chorobą. W późnych wierszach poetki pozostają jedynie ptaki, znów widziane raczej w planie ogólnym, bez zbliżeń. Z ostatniego zbioru, Ogarnąłeś mnie chłodem, odlatują nawet one.

\section{(...)}

Więc zniknij

miń

gdy cień pokrywą się nasunie

i stado ptaków niebem runie

w stronę, gdzie zapadł dzień.

Wahliwej Ręki uczepiony

usiłuj wyczuć puls tej dłoni

wybijającej rytm.

(Rytm (Słowa do pieśni) - Pollakówna 2012a, 493)

Poetka odchodzi samotnie.

Czy wiersze Pollakówny można czytać w perspektywie postantropocentrycznej? Wydaje się, że tak - jeśli tylko policzyć wszystkie występujące w jej poezji gatunki zwierząt (a tych w dwunastu tomach jest ponad pięćdziesiąt), jeśli dostrzec, jak często spostrzeżenia płynące z obserwacji ptaków i owadów stają się dla niej budulcem metafor, wiodącym ku pochwyceniu doświadczenia życia nie tylko w jego filozoficznym, ale i biologicznym wymiarze.

Wydaje się, że nie - jeśli przedstawić ją jako autorkę badającą ludzkie cierpienie, mówiącą o ludzkim poszukiwaniu sensu. Poetkę wzrokocentryczną, korzystającą z kulturowego repertuaru, w którym zwierzętom nadaje się znaczenia symboliczne. Artystkę posługującą się poezją - w którą antropocentryzm wydaje się wpisany. A może niekoniecznie? Mowa wierszy, niekonkluzywna, tworzy przecież przestrzeń spotkania.

Twórczość zorientowana posthumanistycznie jest możliwa tam, gdzie chwieje się „ontologiczna higiena” (Graham, Representations of Post/ human. Monsters, Aliens and Others in Popular Culture, za: Bakke 2010, 17) - gdzie człowiek przestaje być „miarą wszechrzeczy”, a biblijne wezwanie do „czynienia sobie ziemi poddaną” traktuje się jako początek wstydliwej historii o poniżeniu i dyskryminacji. Pollakówna w pytaniach, w zwątpieniach, w nadziei i milczeniu, pozostaje jednak poetką poszukującą Boskiego porządku, traktującą chrześcijański antropocentryzm, tradycję 
metafizyczną (św. Jan od Krzyża) i filozoficzną (św. Augustyn, Pascal) jako ważny punkt odniesienia (Pollakówna 1996, 92).

A przecież te właśnie tropy wiodą jej pisarstwo ku etycznej wrażliwości, zainteresowaniu każdą istotą, poszukiwaniu kontaktu - nawet w obcości. Utwory Pollakówny prowokują lekturę krytyczną, którą podejmuje się w imieniu zwierząt. Autorka dostrzega pokrewieństwo istnień ludzkich i nie-ludzkich. Doświadcza więzi ze stworzeniami uznawanymi za nieistotne, a nawet budzące wstręt, jak owady. Na pytanie o powody takiej perspektywy poetyckiej odpowiadają może najlepiej słowa z encykliki Pochwalony bądź.

Jeśli zbliżamy się do przyrody i środowiska bez tego otwarcia na zadziwienie i podziw, jeśli nie mówimy już językiem braterstwa i piękna w naszej relacji ze światem, to nasze postawy będą postawami władcy, konsumenta lub jedynie wyzyskującego zasoby naturalne, niezdolnego do postawienia ograniczeń swoim doraźnym interesom. Jednakże jeśli czujemy się ściśle związani ze wszystkim, co istnieje, to umiar i troska pojawiają się spontanicznie (Bergoglio 2015, 11-12, podkr. A. Sz-W).

Pytanie o możliwość poezji odnoszącej się do porządku chrześcijańskiego i wartości tradycyjnej zachodniej filozofii, a jednocześnie nieantropocentrycznej wymagałoby wnikliwszej refleksji, której podjęcie przekracza kompetencje literaturoznawcze. Szerzej problem podejmuje Anita Jarzyna (Jarzyna 2015). Kontrowersje związane z nasuwającymi się przy takiej próbie sprzecznościami, a zarazem przestrzeń dialogu, wskazuje Wojciech Bołoz:

Chrześcijanie podkreślają prymat człowieka w świecie i antropocentryzm w filozofii przyrody, zwolennicy ruchów ekologicznych, szczególnie radykalnych, akcentują biocentryzm i równość gatunkową. Różnice te jednak zmniejszają się przez ograniczenie postaw radykalnych, co uwidacznia się w określeniach: antropocentryzm umiarkowany albo biocentryzm umiarkowany... To samoograniczanie się i umiar przedstawicieli różnych filozofii umożliwia wspólne działania na rzecz ochrony środowiska (Bołoz 2010, 8).

Wydaje się, że twórczość Pollakówny można rozważać w kontekście przywołanych przez badacza postaw umiarkowanych. Dwa bieguny refleksji nad zwierzętami w wierszach autorki - przekonanie o wspólnocie i pokrewieństwie i zachwyt ich niemożliwą do pojęcia i oswojenia obcością - są w pewien sposób kompromisowe, dalekie zarówno od akcentowania prymatu człowieka w świecie, jak i od optyki biocentrycznej. Być może na twórczość Pollakówny warto również spojrzeć w kontekście rozważań Ewy Domańskiej o zadaniach posthumanistyki, która nie musi być antyhumanizmem - która szuka odpowiedzi na stawiane w nowym kontekście pytania o to, co to jest życie i co to jest człowiek. Badania posthumanistyczne, według badaczki, mają przekraczać ludzkie ograniczenia - fizyczne i psychiczne - i opisywać anthropos uwikłanego w związki międzygatunkowe i środowiskowe (Domańska 2015, 7-20). 
Człowiek dla Pollakówny jest bytem odrębnym. Ale w odrębności - samotnym i niepewnym. Potrzebującym bliskości. I zawsze gotowym do dialogu.

\section{Bibliografia:}

Agamben Giorgio, 2008, Homo sacer: suwerenna władza i nagie życie, Salwa M. (przeł.), Warszawa.

Bakke Monika, 2010, Bio-transfiguracje. Sztuka i estetyka posthumanizmu, Poznań.

Bakke Monika, 2011, Studia nad zwierzętami: od aktywizmu do akademii i z powrotem?, „Teksty Drugie”, nr 3.

Bakke Monika, 2007, Między nami zwierzętami. O emocjonalnych zwiąkach między ludźmi i innymi zwierzętami, „Teksty Drugie”, nr 1-2.

Bednarek Joanna, 2008, Maszyna antropologiczna - instrukcja demontażu, http://www.nowakrytyka.pl/spip.php?article435.

Bergoglio Jorge Mario , 2015, Pochwalony badź, http://w2.vatican.va/content/ dam/francesco/pdf/encyclicals/documents/papa-francesco $20150524=$ enciclica-laudato-si_pl.pdf.

Bińczyk Ewa, 2007, Nie ma społeczeństwa! „Nasi mniejsi bracia” - społeczne studia nad nauka oraz etyczne zaangażowanie Bruno Latoura, „Teksty Drugie", nr 1-2.

Bołoz Wojciech, 2010, Kościół i ekologia. W obronie człowieka i środowiska naturalnego, Kraków.

Crepaldi Gabriele, 2006, Schiele i ekspresjoniści, Łąkowska D. (przeł.), Warszawa.

Dziewicki Tomasz, 2013, Subiektywny wybór intrygujących obrazów, http://mgzn.pl/articles/view/657.

Gajewska Grażyna, 2015, O władzy ludzi nad zwierzętami w kulturze zachodniej, „Studia Europaea Gnesnensia”, nr 11.

Haraway Donna, 2008, When species meet, Minneapolis.

„Historyka. Studia Metodologiczne”, 2015, Historia w kontekście posthumanistyki, t. 45.

Jarzyna Anita, 2015, Herezje: odzyskiwanie wrażliwości (Tadeusz Nowak, Jerzy Nowosielski), w: Zwierzęta i ich ludzie. Zmierzch antropocentrycznego paradygmatu?, Barcz A., Łagodzka D. (red.), Warszawa.

„Jednak Książki” 2014, Zwierzęcość, Filipowicz A., Żółkłoś M. (red.), nr 4.

Kudyba Wojciech, 2016, Próba bólu. O wierszach Joanny Pollakówny, Warszawa.

Pollakówna Joanna, 1996, Bez rytmu, rozmowę przeprowadziła B. Łopieńska, „Res Publica Nowa”, nr 7/8.

Pollakówna Joanna, 2012, Wiersze zebrane, zebrał, oprac. i wstępem opatrzył J. Zieliński, Mikołów.

Pollakówna Joanna, 2012, Zapatrzenie, Gdańsk. 
Rosochacka Agata, 2012, Nigdy nie byliśmy ludźmi, http://e.czaskultury.pl/ czytanka/literatura/927-nigdy-nie-bylismy-ludzmi.

Rybak Magdalena, 2009, Wielogłos: Czym jest poezja i kto jest poeta??, „WYSPA. Kwartalnik Literacki”, nr 1, http://kwartalnikwyspa.pl/wieloglos-czym-jestpoezja-i-kto-jest-poeta/.

Singer Peter, 2004, Wyzwolenie zwierząt, Alichniewicz A., Szczęsna A. (przeł.), Warszawa.

Strony Joanny Pollakówny, 2016, Kozłowska A., Zieliński J. (red.), Warszawa.

Zwierzęta, gender i kultura. Perspektywa ekologiczna, etyczna i krytyczna, 2014, Barcz A., Dąbrowska M. (red.), Lublin.

Zwierzęta i ich ludzie. Zmierzch antropocentrycznego paradygmatu?, 2015, Barcz A., Łagodzka D. (red.), Warszawa.

\section{O Autorce:}

Agata Szulc-Woźniak - doktorantka na Wydziale Filologii Polskiej i Klasycznej Uniwersytetu im. Adama Mickiewicza w Poznaniu. Pracuje nad monografią twórczości poetyckiej Joanny Pollakówny. Promotorką powstającej rozprawy jest prof. UAM, dr hab. Katarzyna Kuczyńska-Koschany. 
